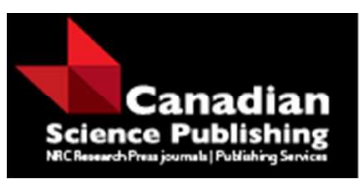

Canadian Journal of Forest Research Revue canadienne de recherche forestière

\title{
Prior wildfires influence burn severity of subsequent large fires
}

\begin{tabular}{|r|l|}
\hline Journal: & Canadian Journal of Forest Research \\
\hline Manuscript ID & cjfr-2016-0185.R2 \\
\hline Manuscript Type: & Article \\
\hline Date Submitted by the Author: & 08-Aug-2016 \\
\hline Complete List of Authors: & $\begin{array}{l}\text { Stevens-Rumann, Camille; University of Idaho, } \\
\text { Prichard, Susan; University of Washington } \\
\text { Strand, Eva; University of Idaho } \\
\text { Morgan, Penelope; University of Idaho }\end{array}$ \\
\hline Keyword: & $\begin{array}{l}\text { fire weather, reburn, repeated wildfires, self-regulation, sequential } \\
\text { autoregression }\end{array}$ \\
\hline & \\
\hline
\end{tabular}

SCHOLARONE $^{\text {Im }}$

Manuscripts 
5 C.S. Stevens-Rumann (Corresponding author), E.K. Strand, P. Morgan

6 University of Idaho

7 Department of Forest, Rangeland, and Fire Sciences

8875 Perimeter Drive MS 1133

9 Moscow, ID 83844

10 Email: csrumann@uidaho.edu

11 Phone: 602-509-5077

12 Fax: 208-885-6564

13

14

15 University of Washington

16 School of Environmental and Forest Sciences

17 University of Washington

18 Seattle, WA 98195-2100 


\section{Abstract}

20 With longer and more severe fire seasons predicted, incidence and extent of fires is

21 expected to increase in western North America. As more area is burned, past wildfires may

22 influence the spread and burn severity of subsequent fires, with implications for ecosystem

23 resilience and fire management. We examined how previous burn severity, topography,

24 vegetation, and weather influenced burn severity on four wildfires, two in Idaho, one in

25 Washington, and one in British Columbia. These were large fire events, together burning

26330,000 ha and cost $\$ 165$ million USD in fire suppression expenditures. Collectively, these

27 four study fires reburned over 50,000 ha previously burned between 1984 and 2006. We used

28 sequential autoregression to analyze how past fires, topography, vegetation, and weather

29 influenced burn severity. We found that areas burned in the last three decades, at any

30 severity, had significantly lower severity in the subsequent fire. Final models included

31 maximum temperature, vegetation cover type, slope, and elevation as common predictors.

32 Across all study fires and burning conditions within them, burn severity was reduced in

33 previously burned areas, suggesting that burned landscapes mitigate subsequent fire effects

34 even with the extreme fire weather under which these fires burned.

35 Key words: fire weather; reburn; repeated wildfires; sequential autoregression; self-

36 regulation 


\section{Introduction}

40 As a self-regulating process, the pattern of previous fires may limit the progression and burn

41 severity of subsequent wildfires for some time due to limited burnable fuels and changes in

42 forest structure (Agee 1999; Peterson 2002; Parks et al. 2014, 2015; Coop et al. 2016). Over

43 the past century, the legacy of past land use changes and fire exclusion have influenced forest

44 landscapes over much of the western United States (Hessburg et al. 2015). After nearly a

45 century of fire exclusion, many dry forests of the western United States have altered stand

46 structures and landscape patterns that can contribute to larger and more severe wildfire

47 events (Hessburg et al. 2015; Parks et al. 2015). With the onset of warmer, drier summers

48 and warm springs, the number and size of wildfires is increasing in the western US and other

49 fire-prone ecosystems throughout the world (Littell et al. 2009; Jolly et al. 2015). Burn

50 severity, defined as the magnitude of ecological effects of fires (Prichard and Kennedy

51 2014), has been less studied than area burned. With the growing number of large wildfires

52 and costly wildfire seasons, a better understanding of fire on fire interactions and their

53 implications for ecological effects is needed to inform science and management of fires.

54 Previous researchers have found that burn severity of wildfires was influenced by the

55 burn severity of prior fire. To date, many of these studies were in large wilderness areas in

56 which wildfires have had limited fire suppression and were managed and monitored (e.g.

57 Collins et al. 2009; van Wagtendonk et al. 2012; Parks et al. 2014). In studies of past fire

58 interactions in the Sierra Nevada Range, Collins et al. (2009) and van Wagtendonk et al.

59 (2012) found that areas previously burned with low to moderate severity within the past 30-

60 years tended to burn at similar severity in a subsequent fire. However, if an area had

61 previously burned in a high severity fire, a high proportion of the area burned at high severity

62 in a subsequent fire. They attributed this to the fire-induced shift in vegetation from forests to

63 highly flammable shrublands rather than simply a function of post-fire fuel accumulation 
64 (van Wagtendonk et al. 2012). Similarly, Holden et al. (2010) found that in wildfires 3 to 14

65 years prior there was a threshold for burn severity above which burn severity is likely to

66 increase in the subsequent fire. Based on inferences from satellite imagery combined with

67 field data, low severity fires often resulted in subsequent low severity fires, but high severity

68 fires resulted in subsequent high severity fires (Holden et al. 2010; Parks et al. 2014a). In this

69 study we focus on non-wilderness areas. Fires outside of wilderness areas are often in drier

70 forest types (Haire et al. 2013), tend to have the highest fire suppression costs, and these

71 areas have high public interest and use.

72 Topography, vegetation, and fire weather influence burn severity of wildfires

73 (Schoennagel et al. 2004; Lentile et al. 2007; Prichard and Kennedy 2014; Birch et al. 2015),

74 but whether these variables supersede or compound the influence of prior fires is not well

75 understood. Previous studies have reported mixed findings on the relative importance of top-

76 down drivers of fire, such as maximum temperature, relative humidity, and wind speeds, and

77 bottom-up drivers, such as vegetation and topography. Bessie and Johnson (1995) and

78 Gedalof et al. (2005) demonstrated that extreme weather conditions can override bottom-up

79 factors, resulting in larger wildfires regardless of fuels and forest types. In contrast, Birch et

80 al. (2015) found that bottom-up factors, including vegetation and site potential, influenced

81 burn severity more than climate and weather. Though multiple researchers have examined

82 bottom-up versus top-down drivers of burn severity, few have analyzed the influence of these

83 factors in previously burned areas over multiple large fires. Some research has found that

84 wildfires burning under very hot, dry, and windy conditions are more likely to overcome fuel

85 breaks even those created by previous wildfires (Pollet and Omi 2002). To better understand

86 the capacity of burn mosaics to be self-regulating, we must understand when and why past

87 wildfires alter subsequent burn severity and when environmental factors or day of burning

88 conditions override the legacy effects of prior fires. 
89 Here we focus on the legacy of previous wildfires by examining the drivers of burn 90 severity within reburned areas in non-wilderness forests of the interior northwestern US. We 91 studied the Tripod Complex Fire (central Washington, USA), the East Zone Complex

92 (central Idaho, USA), Cascade Complex Fires (central Idaho, USA), and Kootenay Fire

93 (central British Columbia, Canada); each of which were unusually large, severe, and

94 expensive relative to those of the prior century, and each burned through areas burned by

95 numerous past fires. We used sequential autoregression (SAR) analysis to evaluate the

96 influence of past wildfires, weather and topography on burn severity. SAR has been used in

97 recent studies of burn severity to take advantage of the inherent spatial autocorrelation in

98 burn severity datasets (Wimberly et al. 2009, Prichard and Kennedy 2013). The effectiveness

99 of fuels treatments, including prescribed fires, have been previously studied on two of these

100 wildfires (Hudak et al. 2011; Prichard and Kennedy 2014), but neither included previous

101 wildfires that may have also modified burn severity. Our study was guided by two key

102 questions: (1) How was burn severity of subsequent wildfires influenced by previous

103 wildfires? and (2) What role does weather, vegetation and topographic conditions have on

104 burn severity? These questions are critical for forecasting the implications for future

105 resilience and vulnerability, as well as understanding how post-fire fuel conditions will

106 influence subsequent burn severity and when and where the legacy of these past burns can be

107 used in wildfire management to achieve vegetation management or restoration goals.

108 Additionally, we address how weather, topography, vegetation, and past wildfires to

109 influence subsequent burn severity and how relationships differ between the four events.

\section{Methods}

111 Study areas

112 We focused our study on four recent, large wildfires in Idaho, Washington, and British

113 Columbia (Figure 1). These wildfires were chosen due to their large size, high fire 
114 suppression costs, and large areas of interactions with previous wildfires. Combined, these

115 four fire complexes burned a total of 330,000 ha and cost over \$165.5 million USD in fire

116 suppression (Filmon 2003; Hudak et al. 2011; Prichard and Kennedy 2015). Our four study

117 fires occurred in years of widespread fires across their respective regions (Filmon 2003;

118 Hudak et al. 2011). In three of the four cases these wildfires were complexes started from

119 multiple ignitions that burned into one another and were managed as a single fire.

120 The 2006 Tripod Complex on the Okanogan-Wenatchee NF in Washington was, at

121 the time, the largest (70,894 ha) fire event in Washington State and cost $\$ 82$ million USD in

122 fire suppression costs (Prichard and Kennedy 2014). Over 65\% of the area burned at

123 moderate to high burn severity with stand replacement. The wildfires in this complex ignited

124 from lightning in high elevation forests of lodgepole pine (Pinus contorta) and Engelmann

125 spruce (Picea engelmannii). The wildfires then spread into surrounding mixed-conifer forests

126 of Douglas-fir (Pseudotsuga menziesii), ponderosa pine (Pinus ponderosa) and western larch

127 (Larix occidentalis). As the Tripod Complex spread northeast with prevailing winds, it

128 burned portions of three 2003 burns, three 2001 burns, and burned a small portion of one

1291994 burn (Figure 2a).

130 The 2003 Kootenay Fire Complex (Kootenay National Park, British Columbia) was

131 one of the largest fire events to have occurred in the Canadian Rockies in park history,

132 burning 17,400 ha and costing $\$ 10.3$ million USD for fire suppression. Over $75 \%$ of the area

133 burned at moderate to high severity. Pre-fire fuel complexes were comprised of mature

134 mixed-conifer forests of lodgepole pine, Engelmann spruce, and subalpine fir (Abies

135 lasiocarpa). This wildfire was mostly stand replacing and burned into a wildfire from 2001

136 (Figure 2b). This fire occurred within a Canadian national park, but full suppression of all

137 wildfires was the standard operating procedure before 2004, thus this fire and those points of

138 interaction were similar to the national forest study areas within the US (Day et al. 1990). 
139 In 2007, the East Zone and Cascade Complex fires each burned over 128,000 ha on

140 the Boise and Payette National Forests in Idaho (Hudak et al. 2011) and cost \$32.5 and \$40.7

141 million USD respectively in fire suppression. The East Zone and Cascade Complexes burned

142 with mixed burn severity, with 21 to $30 \%$ of each wildfire classified as high severity

143 (Stevens-Rumann and Morgan in press). These two complexes burned through a wide range

144 of forest types and elevations from subalpine forests and meadows at high elevation to lower

145 tree line dominated by ponderosa pine woodlands. These two wildfires interacted with 31

146 previous wildfires that burned between 1984 and 2006 (Figure 2c). Although the 2007

147 Cascade and East Zone Complexes shared borders, we analyzed these fires separately given

148 their large size and the computational resources required to analyze these large landscapes.

149 Datasets

150 We used data from multiple sources to examine drivers of burn severity (Table 1).

151 We assessed the impact of previous wildfires by evaluating burn severity using a continuous

152 Relative Differenced Normalized Burn Ratio (RdNBR; Miller et al. 2009) for the three US

153 fires which was obtained from the Monitoring Trends in Burn Severity (MTBS) project

154 (Eidenshink et al. 2007). We chose RdNBR over other metrics of burn severity because it is

155 generally a reliable predictor of field-validated burn severity (Miller et al. 2009; Prichard and

156 Kennedy 2014) and is especially suitable for heterogeneous vegetation (Parks et al. 2015).

157 Additionally, field-based composite burn index (CBI) values on the Tripod Complex Fire

158 were highly correlated with $\operatorname{RdNBR}\left(\mathrm{R}^{2}=0.71\right.$; Prichard and Kennedy 2014). For the

159 Kootenay Fire, we used Differenced Normalized Burn Ratio (dNBR) which was post-

160 processed by Kootenay National Park. Due to the largely homogenous cover type on this fire

161 dNBR was considered to be an appropriate proxy (Miller and Thode 2007).

162 We used the MTBS data for the prior fires for three potential predictor variables.

163 First, we converted continuous RdNBR and dNBR values for past fires into categorical 
164 variables of "unchanged/unburned", "low", "moderate", and "high" using metric specific

165 thresholds established by Miller and Thode (2007) to apply consistent classifications between

166 study areas. For our analysis, categorical variables were required to have a base contrast for

167 regression comparisons, thus we used unburned/unchanged as the base contrast. Second, time

168 since fire was assigned for each pixel that experienced 2 or more fires since 1984. For pixels

169 not previously burned we assigned " 100 " as time since previous fire. We categorized these as

170 "100" years since fire because burn severity data inferred from Landsat satellite imagery is

171 only available after 1984 and most of these forests are known to be dominated by 80-120

172 year old trees (Schellhaas et al. 2001). For pixels that were reburned more than once (i.e.,

173 burned in three or more wildfires between 1984 and 2007), the most recent fire year was used

174 to calculate time since previous fire. This did not occur on the Kootenay Fire and occurred on

175 two percent of the reburned area of the Tripod Fire. On the Cascade Complex Fire this

176 occurred on three percent of reburned pixels and on the East Zone Complex Fires on four

177 percent. Third, to understand possible edge effects, such as fire suppression and changes in

178 fire behavior along a fires perimeter, we used a distance-to-edge metric calculated as the

179 distance of each pixel to the nearest burn perimeter. Although fire management actions

180 during wildfires likely altered fire extent and burn severity, we did not account for them

181 directly as the records of management actions were incomplete.

182 We were able to partially evaluate RdNBR accuracy in reburned areas by examining

183 relationships between field-based Composite Burn Index values and RdNBR values in reburn

184 areas of the 2006 Tripod Complex fires. Field validation plots were established in prescribed

185 burn areas that reburned in the Tripod Complex, and most were classified as low burn

186 severity areas as a result of the treatment effect (Prichard and Kennedy 2014). On these sites,

187 producer's accuracy was around $40 \%$, however $95 \%$ of the misclassification occurred when

188 RdNBR values were close to the burn severity cut-off between unchanged and low or low 
189 and moderate severity established by Miller and Thode (2007). Field validation did not differ

190 from that inferred from satellite imagery by more than one category (e.g., low severity

191 classification when field validation was moderate severity).

192 To examine the impact of weather on the day of burning, we acquired fire progression

193 interval layers from the Okanogan-Wenatchee, Boise, and Payette National Forests, and from

194 Kootenay National Park. These progression layers allow us to narrow the time frame within

195 which each pixel burned to a 10-96 hour window depending on the frequency progression

196 intervals were sampled from infrared imagery. We then assigned weather characteristics

197 during each progression interval based on the date each pixel burned. We assigned maximum

198 and average wind taken at $6.1 \mathrm{~m}$ above ground, maximum and average air temperature, and

199 minimum relative humidity $(\mathrm{RH})$. These data were acquired from nearby Remote Area

200 Weather Stations (RAWS): the First Butte station for the Tripod, the Tea Pot Idaho station

201 for the Cascade and East Zone (Western Regional Climate Center, http://www.raws.dri.edu/,

202 last accessed January 13, 2015), and Vermillion Weather Station (courtesy of Parks Canada,

203 Kootenay National Park). All stations were within $5 \mathrm{~km}$ of the nearest burned edge. From the

204 Vermillion weather station, we could only acquire daily mean temperatures, relative

205 humidity, and average wind speed; therefore maximum and minimum values were not

206 available and excluded from the analysis.

207 Vegetation and fuels information was derived from LANDFIRE products (30m

208 resolution; Ryan and Opperman 2013). We used 2001 data to reflect the best data for

209 conditions prior to the three study wildfires. We acquired crown bulk density (CBD), fire

210 regime group (FRG) and canopy cover (CC). We also converted the 40 existing vegetation

211 type (EVT) to seven "cover type" categories, to group similar vegetation types. These cover

212 types were "lodgepole pine", "ponderosa pine", "subalpine forest", "riparian”, "dry-mesic

213 mixed-conifer", "Douglas-fir/western hemlock", "grassland/shrubland”. Grasslands and 
214 shrublands comprised a relatively small portion of the total study area landscapes with $8 \%$ on

215 the Tripod, $15 \%$ on the East Zone, and $18 \%$ on the Cascade thus we grouped all grasslands

216 and shrublands together for the analysis, even though conditions of these various grassland

217 and shrubland covertypes are known to be highly variable: from subalpine grasslands to low

218 elevation shrublands and grasslands. We used "dry mesic mixed-conifer" as the base contrast

219 for burn severity comparison. Vegetation type and stand origin maps are available from

220 Kootenay National Park, but due to the fairly uniform vegetation types and stand structures

221 we did not include vegetation characteristics for this model.

222 Topographic and landscape indices were evaluated, including potential incoming

223 solar radiation summarized over one calendar year period (Fu and Rich 1999), elevation (m),

224 slope (degrees; ESRI 2011), and steady state topographic wetness index (TWI). TWI was

225 derived using Evans' (2003) script. Three topographic position indices including topographic

226 position index (TPI), ridge/ridge-like position, and valley/valley-like position, were

227 calculated within a 100-m neighborhood of each pixel using methods developed by Weiss

228 (2001). The basic TPI calculation compares the elevation of each cell in a DEM to the mean

229 elevation within the nearest-neighborhood of each pixel. Ridgetop or ridge-like positions are

230 defined as positive TPI values (0-2.0), representing locations that are higher than the average

231 of their surroundings, and valley or valley-like positions defined as negative TPI values (-2 to

$2320)$.

233 Data Analysis

234 We used Sequential Autoregression (SAR) analysis (Wimberly et al. 2009) to

235 evaluate how previous burn severity, topography, vegetation, and weather, influenced burn

236 severity. Our response variable was burn severity on each of our four study fires represented

237 by continuous RdNBR or dNBR values. Candidate predictor variables included: weather

238 variables, burn severity classification of past wildfire events (e.g., unchanged/unburned, low, 
239 moderate, and high), time since previous fire, topographic variables, vegetation types, and

240 fuel characteristics (Table 1). We examined colinearity between possible predictor variables

241 with simple pairwise correlations and excluded correlated variables $(r>0.85$; Nash and

242 Bradford 2001) from the same model. The SAR models were constructed in R programming

243 language (R Development Core Team 2011) and methods were published by Wimberly et al.

244 (2009) and Prichard and Kennedy (2014). We compared individual variable models using

245 Akaike's Information Criterion (AIC; Akaike 1974), and selected the final multivariate

246 models based on lowest AIC values. We tested multiple models and removed variables when

247 the AIC value was not reduced by more than 50 (Supplementary Table 1).

$248 \quad$ Prichard and Kennedy (2014) demonstrated that using a 30m nearest neighborhood

249 distance minimized both AIC and Moran's I, and we confirmed with Moran's I that our final

250 models did not have autocorrelation of the residuals at this neighborhood distance. Although

251 SAR analyses define the SAR neighborhood weighted matrix by subsampling to reduce

252 computational resources and time (Kissling and Carl 2008), we assigned point data

253 information to each 30-m pixel across the entirety of each of our four study fires, including

254 areas previously unburned. In the Cascade and East Zone Complex, a spatially continuous

255 dataset was impossible due to a failure of the Landsat 7 EMT+ scan line correction

256 mechanism (known as SLC off condition; Howard and Lacasse 2004; Supplementary Figure

257 1). In these two wildfires, we used all available points, skipping the $150-\mathrm{m}$ scan line areas

258 and treating pixels surrounding the scan lines as true neighbors. To address the possibility

259 that missing data skewed results of our SAR analysis, we performed a test of bias by

260 examining the distribution of cover type and topographic variables within these scan lines

261 versus areas with RdNBR data. Our examination of pixels within and outside the scan lines

262 showed that the distribution of canopy cover, elevation, slope, solar radiation and

263 topographic wetness index were nearly identical for both the Cascade and East Zone 
264 Complex fires (Figure 3), and therefore that there was no bias due to scan line errors.

265 In addition to examining these fires as continuous study sites, across all cover types

266 we did two additional SAR analyses within each study fire to determine how past fires

267 influenced burn severity within different forest types, we refer to these as "cover type

268 models". To extract data for these analyses we grouped our previous cover types into "low

269 elevation forest type" (Douglas-fir/hemlock, ponderosa pine, dry-mesic mixed-conifer) and a

270 "high elevation forest type" (lodgepole pine, subalpine fir), and ran the SAR analysis on only

271 points that fell within each of these broad forest type classifications. Only two factors were

272 considered in this model: time since previous fire and past burn severity.

\section{Results}

274 Final SAR models of burn severity, based on lowest AIC values, varied between 275 study areas, but past burn severity was a strong predictor on all sites. The Tripod, Cascade 276 and East Zone SAR models included distance to edge, valley bottom, maximum temperature, 277 and cover type (Table 2 and 3). In addition to these common five variables, the final model

278 for Tripod included canopy cover, elevation, and slope. The East Zone final model also 279 included elevation, TWI, and maximum wind gusts on day of burning and the Cascade final 280 model included slope, time since fire, maximum wind gusts on day of burning, and canopy 281 cover. The Kootenay fire did not have vegetation variables; the final model included distance 282 to edge, hill, elevation, average temperature and past burn severity. Many other predictor 283 variables were significant predictors of RdNBR or dNBR but were not included in the final 284 models, based on lowest AIC values.

285 Past wildfires

286 Past burn severity had a negative relationship on subsequent burn severity on all four 287 study fires. Compared to areas unburned/unchanged in previous fires, previously burned 288 pixels had reduced burn severity (Table 3, Figure 4). Areas that burned at high severity in the 
289 Tripod and Kootenay fires contributed to the largest reduction in burn severity in the 290 subsequent fire, while low burn severity areas had the smallest reduction or did not differ 291 significantly from previously unburned/unchanged points. Conversely, on the East Zone and 292 Cascade fires, areas that previously burned at low severity had the largest reduction in reburn 293 severity compared to unburned areas.

294 Slightly different results were observed in the cover type models. The relationship to 295 past burn severity was maintained within both low elevation and high elevation forest types 296 on the Tripod, but the estimates on East Zone and Cascade fires varied from the full models. 297 On the East Zone, high elevation forest types had the largest decreases in burn severity on 298 sites previously burned at high severity, while low elevation forest types experienced the 299 lowest burn severity after previously experiencing a low severity fire. On the Cascade fire the 300 pattern was the same in both forest types: the lowest burn severity was observed after 301 previously experiencing a low severity fire, while areas that experienced a high severity fire 302 had significantly higher burn severity than unburned areas. (Table 4)

303 Distance to edge was a significant predictor and had a positive relationship on burn 304 severity, reflecting that regardless of whether sites were previously burned, interior regions 305 of these large fires had higher burn severity than the perimeters. This applied to all four fires 306 we studied.

307 Time since past fire had mixed effects in the various models. On the Cascade fire 308 burn severity was lower the longer time since fire, and though significant it was not included 309 in the East Zone or Cascade models due to only small decreases in the best model AIC 310 values. However, in the cover type models when forest types were analyzed individually, 311 time since past fire proved to have a positive relationship on all three study areas (Table 4). 312 Fire weather, vegetation, and topography

313 Of the weather variables analyzed, the most important predictors of burn severity 
314 were maximum temperature and minimum RH on the Tripod, average temperature and

315 average RH on the Kootenay, and maximum temperature and maximum wind speed on the

316 East Zone and Cascade fires. Because temperature and relative humidity were highly and

317 inversely correlated, only maximum temperature, the stronger of the two predictors based on

318 lower AIC values, was included in the final model for the Tripod. Maximum temperature and

319 maximum wind speed were included in the final model for the East Zone and Cascade. Burn

320 severity was positively correlated with maximum temperature, but the relationship to

321 maximum wind gust was mixed on the different study areas. On the East Zone Complex

322 higher burn severity was correlated with higher maximum wind speeds, but a negative

323 correlation was observed with burn severity on the Cascade Complex.

324 Of the LANDFIRE variables, vegetation canopy cover and cover type were the most

325 important predictors of burn severity (Table 3). Forest canopy bulk density was also a

326 significant predictor. However, because of the high correlation between canopy cover and

327 canopy bulk density, only canopy cover was included in the final models. Valley bottom,

328 ridge top, and TPI metrics were significant predictors of burn severity. Valley bottom, which

329 was inversely correlated to ridge top, was included in final model for the Tripod, East Zone,

330 and Cascade study areas because it was a better predictor. Valley bottom was inversely

331 related to burn severity; valley bottoms burned less severely than ridges and steep slopes. TPI

332 was highly correlated with both of these metrics and was therefore excluded in the final

333 model on these three fires. On the Kootenay Fire, TPI was significant and the best predictor

334 but was excluded from the final model because it only minimally reduced the model AIC

335 value.

336 Elevation was a significant predictor of burn severity on the Tripod, East Zone, and

337 Kootenay fires. Burn severity was positively correlated with elevation on these three fires,

338 with increasing burn severity at higher elevations up to $2150 \mathrm{~m}$ on the Tripod, $2450 \mathrm{~m}$ on the 
339 Cascade, $2550 \mathrm{~m}$ on the East Zone, and 2075m on the Kootenay. Above these elevations,

340 burn severity decreased across the highest elevations of each fire area (Figure 5).

341 As slope and TWI were highly correlated, and slope was a slightly stronger predictor

342 than TWI for the Tripod and Cascade (Table 3). Slope was positively related to burn severity

343 on the Tripod and negatively related to burn severity in the Cascade and Kootenay. For East

344 Zone, TWI was the stronger predictor and was inversely related to burn severity.

\section{Discussion}

346 Within each study area, top-down drivers such as weather (high temperatures, high

347 windspeeds and low relative humidity) influenced fire effects as did bottom-up factors

348 including topography, vegetation type and past wildfire effects (Parisien et al. 2011; Birch et

349 al. 2015). Over the coming decades, the ecological footprint of heterogeneous burn severity

350 patterns will contribute to the mosaic of vegetation response and will likely influence future

351 landscape dynamics.

352 Evidence of self-regulation in past burns

353 The drivers of burn severity were remarkably similar across these four large and

354 different landscapes, each with different land uses and fire history legacy. As these large fires

355 burned across diverse topography and vegetation, burn severity generally was reduced by

356 previous wildfires (Figure 4). Surface fuels and tree density, critical to fire behavior, were

357 likely reduced on these previously burned areas (Stevens-Rumann and Morgan in press).

358 Lower fuel connectivity may have led to associated reductions in subsequent fire behavior

359 and effects (Alexander and Cruz 2012). While the reduction in fuel may be beneficial from a

360 fire suppression stand point, these changes in fuel may indicate large changes in vegetation

361 type (e.g. Stevens-Rumann and Morgan in press; Harvey et al. 2016)

362 Although lower burn severity was observed in previously burned areas on all four

363 study sites, the impact of prior burn severity varied by study site (Figure 4a and b). The 
364 results from Tripod and Kootenay directly contrasts with recent studies in which low to

365 moderate previous burn severity resulted in a reduction in subsequent burn severity but high

366 severity fires were often followed by high severity fires (Collins et al. 2009; Holden et al.

367 2010; Parks et al. 2014a; Harvey et al. 2016). Differences may be explained by slow

368 vegetation response in the Tripod and Kootenay compared to other study locations, such as

369 Yosemite National Park, where flammable shrub fields can regenerate rapidly following high

370 burn severity fire (Collins et al. 2009; van Wagtendonk et al. 2012). Another potential reason

371 for this difference may be that our study areas are outside of wilderness and experienced

372 different fire suppression actions and prior land uses. Fire suppression on the edge of the past

373 fires, including containment lines and burnout operations, may have effectively reduced fire

374 spread and/or decreasing subsequent burn severity, especially within older wildfires. We

375 could not account for this except with our distance to edge metric due to the lack of

376 geospatial data of fire suppression activities.

377 In forested cover types, burn severity increased as the time since fire increased on all

378 study fires, and this relationship was generally strongest in dry forest types (Table 4), as was

379 reported by others (Holden et al. 2010; Haire et al. 2013; Parks et al. 2014). In these

380 ecosystems with shorter fire return intervals, previously burned areas only act as barriers or

381 mitigate burn severity for short periods of time due to rapid accumulations of grasses, other

382 herbs, shrubs and fine wood (e.g. Peterson 2002; Parks et al. 2015).

383 Patches of stand-replacing fire or areas maintained by frequent surface fires create

384 fuel heterogeneity that may reduce subsequent fire spread or burn severity (Hessburg et al.

385 2015). The marked decrease in burn severity across most previously burned areas supports

386 this concept. In both high elevation, moist forests and low elevation, dry forests on the East

387 Zone, Tripod, and Kootenay Fires, high burn severity in an initial fire resulted in lower burn

388 severity in subsequent fires, with the exception of forested cover types on the Cascade. 
389 Although other variables were also important to our predictive models of burn severity, large

390 decreases in burn severity associated with previous severity indicates that these altered

391 landscapes are less likely to burn severely again within the first two decades following a fire

392 (Hudak et al. 2010; Prichard and Kennedy 2014; Harvey et al. 2016).

393 The capacity of past burn mosaics to self-regulate is not well understood given the

394 deficit of fire in many dry forest landscapes over the past century (Hessburg et al. 2007;

395 Marlon et al. 2012). Fire on fire interactions are still relatively uncommon across dry forest

396 landscapes but will become more prevalent in the coming decades as wildfires continue with

397 warmer, drier summers predicted for much of the western United States (Littell et al. 2009;

398 Cansler and McKenzie 2014). The amount of area reburned in our study landscapes was

399 small (roughly $3 \%$ of the total fire area), but proportion of areas reburned will likely increase

400 with climate change. Fire activity has already dramatically increased in the past decade, with

4013.7 million ha burned nationally in $2015,45 \%$ more than the previous 10 -year average

402 (http://www.nifc.gov).

403 Because previous wildfires mitigated burn severity under extreme conditions, we

404 expect past wildfires to be particularly effective at shaping landscapes when subsequent fires

405 burn under less extreme fire weather (Pollet and Omi 2002). Past wildfires can alter burn

406 severity and even fire spread, acting as temporary fuel breaks (Teske et al. 2012; Haire et al.

407 2013; Parks et al. 2014, 2015), and a single fire may be sufficient to initiate self-regulation.

408 However, large stand-replacing wildfires also may result in a large, homogenous area of

409 similar fuels that, in the absence of subsequent finer-scale disturbances, could predispose

410 landscapes to subsequently large fire events that further homogenize landscapes (Peterson

411 2002). Smaller fires, in particular, may be critical to creating landscape patterns that would

412 be less conducive to burning in subsequent large, stand-replacing events (Hessburg et al.

413 2015) and prevent large vegetation type conversions (Harvey et al. 2016; Stevens-Rumann 
414 and Morgan in press). Currently, a common fire management strategy is to suppress all

415 wildfires. However, fires that burn under mild or average weather conditions may provide

416 critical heterogeneity in vegetation cover and structure that mitigates area burned and

417 patterns of burn severity in subsequent wildfires (Hessburg et al. 2015, Kemp et al. 2015).

418 Fire weather

419 In general, higher temperatures, lower relative humidity and in some cases stronger

420 winds were related to higher burn severity (Table 3). Our results suggest that on more

421 extreme weather days, fires burn more severely, fueled by reduced thresholds to burning and

422 the influence of wind on fire spread and intensity (Birch et al. 2015; Cansler and McKenzie

423 2014). The weather variables, broadly summarized from nearby weather stations, in the final

424 models suggests that nearby weather stations may be a decent proxy for finer-scale, fire-

425 weather relationships (Prichard and Kennedy 2014). However, we found some inconsistent

426 relationships: on the East Zone fire burn severity increased with higher winds, while the

427 opposite relationship was observed on the Cascade. Fine-scale variability in weather patterns

428 were undetectable using coarse-scale data and may be the reason for this inconsistent

429 relationship (Taylor et al. 2004). Although progression maps allowed us to relate burn

430 severity at a pixel to the weather at the general time of burning, progression intervals varied

431 from $<24$ hours to four days of burning, and the weather conditions at the time a given pixel

432 burned could be poorly represented by summarized weather over the progression interval.

433 Vegetation

434 Denser, closed-canopy forests burned at higher severity than open canopy forests, as

435 would be expected from past studies (Schoennagel et al. 2004). Severity was highest in the

436 high elevation forest types (Table 3 and 4). Multi-layered, conifer forests dominated by thin-

437 barked trees burn with a higher proportion of high severity, stand-replacing fires and are

438 characterized by either mixed or high-severity fire regimes (Bigler et al. 2005; Prichard and 
439 Kennedy et al. 2014). In contrast, dry, low elevation forest types (i.e., dry-mesic mixed-

440 conifer, ponderosa pine, Douglas-fir cover types) generally burned at lower burn severity on

441 the Tripod, Cascade, and East Zone fires.

442 Burn severity in grasslands and shrublands was more severe than dry-mesic mixed

443 conifer forests. Given the variation among and within these grouped vegetation types from

444 alpine meadows to low elevation grasslands/shrublands interpretation may be difficult and

445 skew relationships with burn severity. Additionally, burn severity is known to be difficult to

446 infer from satellite imagery one-year post-fire in many of these grass and shrub cover types

447 given the rapid vegetation recovery within one year (van Wagtendonk et al. 2012).

448 Topography

449 Across study sites, we found that burn severity was related to topographic variables

450 including slope gradient, elevation and TWI (Table 3). Across all sites, burn severity

451 increased as slope gradient increased, which is corroborated by other studies (e.g. Birch et al.

452 2015). Burn severity decreased as TWI increased, similar to other studies (Holden et al.

453 2009). These relationships may be related to changes in fire behavior across topographical

454 and moisture gradients. As wildfires spread up steep, drier slopes, fire intensity generally

455 increases, transition from surface to crown fire is more possible, and rate of spread and flame

456 lengths increase (Scott and Reinhardt 2001). Airflow in valley bottoms is also sometimes

457 restricted and may be related to generally lower burn severity in valley-like settings (Finney

458 and McAllister 2011).

459 The positive correlation between burn severity and elevation is likely a result of fuel

460 moisture gradients and differences in vegetation types. Low elevation areas of the Cascade,

461 East Zone and Tripod fires were dominated by relatively fire-resistant, thick-barked species

462 such as ponderosa pine and mature Douglas-fir. Conversely, mid- to high elevation areas

463 were dominated by higher density mixed conifer forests dominated by thin-barked species 
464 such as lodgepole pine and subalpine fir that are more readily killed by even low intensity

465 fires (Agee 1999). Across forested areas of the western US, as elevation increases so do fire 466 return intervals and the proportion of high burn severity when fires occur (Schoennagel et al 467 2004).

468 The highest elevations in our study areas generally had low burn severities that were 469 comparable to the burn severity of low elevation sites (Figure 5). Subalpine and alpine areas 470 often have higher fuel moisture, lower temperature, higher relative humidity, and less

471 burnable vegetation at or above tree line (Schoennagel et al. 2004). Reduced burn severity at 472 the highest elevations was especially demonstrated in the Kootenay and Tripod study areas.

473 On the Kootenay fire, burn severity declined above approximately $2100 \mathrm{~m}$ elevation. On the

474 Tripod Complex, post-burn imagery indicated that subalpine meadows did not burn; the 475 subsequent fires burned around subalpine meadows or only consumed tree islands within 476 them.

\section{Conclusions}

478 Our study provides strong evidence that the landscape patterns created by past

479 wildfires influenced subsequent wildfire burn severity, creating a landscape legacy of burn

480 mosaics. While many factors influence burn severity, previous wildfires reduced burn

481 severity on all four subsequent large fires. Considering the extreme fire weather under which

482 these fires burned, it is important to note that the bottom-up factors of past fires, vegetation,

483 and topography influenced burn severity. Our research supports the consideration of

484 managing wildfires to burn into previously burned landscapes as these may continue to

485 reduce burn severity under most fire weather conditions and allow fire to return to fire-prone 486 landscapes (Hessburg et al. 2015).

487 Because we studied wildfires in non-wilderness areas, the study areas provide some 488 insights into the influence of past wildfires during operational management of on-going, 
489 large wildfires. For example, during the 2003 Kootenay Fires, the 1968 Vermillion Fire was

490 effectively used in a burnout operation to halt the eastward spread of Kootenay Complex into

491 old-growth Engelmann spruce and subalpine fir forests of the Bow Valley and Banff

492 National Park (Rick Kubian, Parks Canada, personal communication). Fires in Idaho in

493 recent decades have been extensive, with over $46 \%$ of the Boise National Forest burned since

494 1984. In response, some incident management teams are making strategic decisions to take

495 advantage of where previous fires may limit the spread of subsequent fires (Bob Schindelar,

496 Boise National Forest, personal communication). Likewise, even during large fire spread

497 days, the 2006 Tripod Complex fire was corralled by several recent wildfires that occurred

498 from 1994-2003 and even the 1970 Forks fire which was composed of young, regenerating

499 lodgepole pine with sparse surface fuels (Gray and Prichard 2015). Following the 2006

500 Tripod fire, two subsequent wildfires, including the 2014 Carlton Complex and the 2015

501 Okanogan Complex, shared borders with the Tripod perimeter and these were the only parts

502 of the fire complexes that were not actively suppressed. Incident command communicated to

503 the public that there were insufficient fuels to carry active fire spread within the Tripod burn

504 area, and while the wildfires burned to the edge of the Tripod burn area, they did not advance

505 into the recently burned landscapes.

506 Previously burned areas are considered in both active fire management

507 (http://wfdss.usgs.gov/wfdss/WFDSS_Home.shtml last accessed 28 June 28, 2016) and in

508 achieving land management goals. Given the rising cost of fire suppression (Calkin et al.

509 2015), knowing when and where areas are expected to burn less severely can help to reduce

510 the costs of future large wildfire events while assisting land managers in making the fire

511 management decisions consistent with land management plans and restoration priorities

512 (Hessburg et al. 2015). Wildfires, even the large fire events studied here, possess some

513 attributes of self-regulation, and managing for the interaction of these events can contribute 
514 to restoring the resilience of fire-prone landscapes. Allowing more wildfires to burn,

515 especially in dry forest types, may not only serve land management by potentially mitigating

516 future burn severity, but also promote more fire resilient landscapes that can withstand the

517 impacts of repeated disturbances that will become ever more present with climate change.

518 
520 We thank A. Arnold, T. Zalesky, and J. Romain for assistance with field data

521 collection and the Okanogan-Wenatchee, Payette, and Boise National Forests and National

522 Parks Canada personnel, including M. Pillers and S. Kovach, for local information and data

523 layers. We thank B. Salter, K. Konis, and R.Gray for assistance with data acquisition, and C.

524 Hoffman, P. Hessburg, J. Hicke and anonymous reviewers for their helpful reviews. Funding

525 was provided by Joint Fire Science Program (Project \# 14-1-02-33 and the USDA Forest

526 Service Rocky Mountain Research Station under agreements RJVA \# 14-JV-11261987-047

527 and 12-JV-11221637-136, Modification \#1.

528 


\section{References}

530 Agee, J. K. 1999. Fire effects on landscape fragmentation in interior west forests. In Forest 531 fragmentation: Wildlife and management implications. Edited by J. A. Rochelle, L. 532 A. Lehmann, and J. Wisniewski. Koninklijke Brill NV, Leiden, The Netherlands. $533 \quad$ pp.323.

534 Akaike, H. 1974. A new look at the statistical model identification. IEEE Transactions on $535 \quad$ Automatic Control 19:716-723.

536 Alexander, M.E. and Cruz, M.G. 2012. Interdependencies between flame length and fireline 537 intensity in predicting crown fire initiation and crown scorch height. Int. J. Wildland 538 Fire. 21: 95-113.

539 Bessie, W.C. and Johnson, E.A. 1995. The relative importance of fuels and weather on fire 540 behavior in subalpine forests. Ecology 76(3): 747-762.

541 Bigler, C., Kulakowski, D., and Veblen, T.T. 2005. Multiple disturbance interactions and 542 drought influence on fire severity in Rocky Mountain subalpine forests. Ecology 86: $543 \quad 3018-3029$.

544 Birch, D.S., Morgan, P., Kolden, C.A., Abatzoglou, J.T., Dillon, G.K., Hudak, A.T., and 545 Smith, A.M.S. 2015. Vegetation, topography and daily weather influenced burn 546 severity in central Idaho and western Montana forests. Ecosphere 547 6:art17. http://dx.doi.org/10.1890/ES14-00213.1

548 Calkin, D.E., Thompson, M.P. and Finney, M.A. 2015. Negative consequences of positive 549 feedbacks in US wildfire management. Forest Ecosystems 2: 9.

550 Cansler, C.A., and McKenzie, D. 2014. Climate, fire size, and biophysical settings control 551 fire severity and spatial pattern in the northern Cascade Range, USA. Ecol. Appl. 24: 
553 Collins, B.M., Miller, J.D., Thode, A.E., Kelly, M., van Wagtendonk, J.W., Stephens, S.L. 554 2009. Interactions among wildland fires in a long established Sierra Nevada natural 555 fire area. Ecosystems 12: 114-128.

556 Coop, J.D., Parks, S.A., McClernan, S.R., Holsinger, L.M. 2016. Influences of prior wildfires 557 on vegetation response to subsequent fire in a reburned southwestern landscape. Ecol. $558 \quad$ Appl. 26: 346-354.

559 Day, D., White C.A., and Lopoukhine, N. 1990. Keeping the flame: fire management in the 560 Canadian Park Service. Ill: Proc. Interior West Fire Council Annual Meeting. $561 \quad$ Kananaskis Village, Alberta.

562 Eidenshink, J., Schwind, B., Brewer, K., Zhu, Z., Quayle, B., Howard, S. 2007. A project for 563 monitoring trends in fire severity. Fire Ecology. 3: 3-21.

564 ESRI. 2011. ArcGIS Help 10.0, Hillshade and Slope (Spatial Analyst).

565 Evans, J. 2003. Compound topographic index script. http://arcscripts.esri.com.

566 Filmon, G. 2003. Firestorm 2003 Provincial review. Last accessed 24 September, 2015 567 http://bcwildfire.ca/History/ReportsandReviews/2003/FirestormReport.pdf.

568 Finney, M.A. and McAllister, S.S. 2011. A review of fire interactions and mass fires. Journal $569 \quad$ of Combustion 2011:548328.

570 Gedalof, Z.M., Peterson, D.L., Mantua, N.J. 2005. Atmospheric, climatic, and ecological 571 controls on extreme wildfire years in the northwestern United States. Ecol. Appl. 15: $572 \quad 154-174$

573 Gray, R.W., and Prichard, S.J. 2015. A tale of two fires: The relative effectiveness of past 574 wildfires in mitigating wildfire behavior and effects. USDA, Forest Service, Rocky 

Mountain Research Station, Proc. RMRS-P-73, Fort Collins, CO.

576 Haire, S.L., McGarigal, K., and Miller, C. 2013. Wilderness shapes contemporary fire size 577 distributions across landscapes of the western United States. Ecosphere 4(1): 15 $578 \quad$ http://dx.doi.org/10.1890/ES12-00257.1.

579 Harvey, B. J., D. C. Donato, and M. G. Turner. 2016. Burn me twice, shame on who?

580 Interactions between successive forest fires across a temperate mountain region. $581 \quad$ Ecology: in press.

582 Hessburg, P.F., Salter, R.B., James, K.M. 2007. Re-examining fire severity relations in pre583 management era mixed-conifer inferences from landscape patterns of forest structure. $584 \quad$ Landscape Ecol. 22: 5-24.

585 Hessburg, P.F., Churchill, D.J., Larson, A.J., Haugo, R.D., Miller, C., Spies, T.A., North, 586 M.P., Povak, N.A., Belote, T., Singleton, P.H., Gaines, W.L., Keane, R.E., Aplet, 587 G.H., Stephens, S.L., Morgan, P., Bisson, P.A., Rieman, E., Salter, R.B., Reeves, 588 G.H. 2015. Restoring fire-prone Inland Pacific landscapes: seven core principles. $589 \quad$ Landscape Ecol. 30: 1805-1835.

590 Holden, Z.A., Morgan, P., and Evans, J.S. 2009. A predictive model of burn severity based 591 on 20-year satellite-inferred burn severity data in a large southwestern US wilderness area. Forest. Ecol. Mang. 258: 2399-2406.

593 Holden, Z.A., Morgan, P., Hudak, A.T. 2010. Fire severity of areas reburned by wildfires in 594 the Gila National Forest, New Mexico, USA. Fire Ecology 6: 77-85.

595 Howard, S.M., and Lacasse, J.M. 2004. An evaluation of gap-filled Landsat SLC-Off 596 imagery for wildfire burn severity mapping. Photogramm. Eng. Rem. S. 70: 877-880.

597 Hudak, A.T., Rickert, I., Morgan, P., Strand, E., Lewis, S.A., Robichaud, P.R., Hoffman, C., 
598

599

600

601

602

603

604

605

606

607

608

609

610

611

612

613

614

615

616

617

618

619

620

and Holden, Z.A. 2011. Review of fuel treatment effectiveness in forests and rangelands and a case study from the 2007 megafires in central Idaho, USDA, Forest Service Rocky Mountain Research Station, Gen. Tech. Rep. RMRS-GTR-252 Fort Collins, CO.

Jolly, W.M., Cochrane, M.A., Freeborn, P.H., Holden, Z.A., Brown, T.J., Williamson, G.J., and Bowman, D.M. 2015. Climate-induced variations in global wildfire danger from 1979 to 2013. Nature Comm. 6.

Kissling, W., and Carl, G. 2008. Spatial autocorrelation and the selection of simultaneous autoregressive models. Global Ecol. Biogeogr. 17: 59-71.

Lentile, L.B., Morgan, P., Hudak, A.T., Bobbitt, M.J., Lewis, S.A., Smith, A.M.S., and Robichaud, P.R. 2007. Post-fire burn severity and vegetation response following eight large wildfires across the western United States. Fire Ecology. 3(1): 91-101.

Littell, J.S., McKenzie, D., Peterson, D.L., and Westerling, A.L. 2009. Climate and wildfire area burned in western U.S. ecoprovinces, 1916-2003. Ecol. Appl. 19: 1003-1021.

Marlon, J.R., Bartlein, P.J., Gavin, D.G., Long, C.J., Anderson, R.S., Briles, C.E., Brown, K.J., Colombaroli, D., Hallett, D.J., Power, M.J., Scharf, E.A., and Walsh, M.K. 2012. Long-term perspective on wildfires in the western USA. P. Natl. Acad. Sci. USA. 109 (9): E535-E543.

Miller, J.D., Knapp, E.E., Key, C.H., Skinner, C.N., Isbell, C.J., Creasy, R.M., and Sherlock, J.W. 2009. Calibration and validation of the relative differenced Normalized Burn Ratio (RdNBR) to three measures of fire severity in the Sierra Nevada and Klamath Mountains, California, USA. Remote Sens. Environ. 113: 645-656.

Miller, J.D., and Thode, A.E. 2007. Quantifying fire severity in a heterogeneous landscape 
with a relative version of the delta Normalized Burn Ratio (dNBR). Remote Sens.

$622 \quad$ Environ. 109: 66-80.

623 Parisien, M.A., Parks, S.A., Miller, C., Krawchuck, M.A., Heathcott, M., and Moritz, M.

624 2011. Contributions of ignitions, fuels, and weather to the spatial patterns of burn

625 probability of a boreal landscape. Ecosystems. 14: 1141-1155.

626 Parks, S.A., Holsinger, L.M., Miller, C., and Nelson, C.R. 2015. Wildland fire as a self-

627 regulating mechanism: the role of previous burns and weather in limiting fire

628 progression. Ecol. Appl. 25(6): 1478-1492.

629 Parks, S.A., Miller, C., Nelson, C.R., and Holden, Z.A. 2014. Previous fires moderate fire

630 severity of subsequent wildland fires in two large western US wilderness areas.

$631 \quad$ Ecosystems 17: 29-42.

632 Peterson, G.D. 2002. Contagious disturbances, ecological memory, and the emergence of $633 \quad$ landscape pattern. Ecosystems 5: 329-338.

634 Pollet, J., and Omi, P.N. 2002. Effect of thinning and prescribed burning on crown fire 635 severity in ponderosa pine forests. Int. J. Wildland Fire 11: 1-10.

636 Prichard, S.J., and Kennedy, M.C. 2014. Fuel treatments and landform modify landscape 637 patterns of burn severity in an extreme fire event. Ecol. Appl. 24(3):571-590.

638 R Development Core Team. 2011. R: a language and environment for statistical computing.

639 R Foundation for Statistical Computing, Vienna, Austria. www.r-project.org.

640 Ryan, K.C., and Opperman, T.S. 2013. LANDFIRE-A national vegetation/fuels data base for 641 use in fuels treatment, restoration, and suppression planning. Forest. Ecol. Mang. 294:

$642 \quad 208-216$.

643 Schellhaas, R., Spurbeck, D., Ohlson, P., Keenum, D. and Riesterer, H. 2001. Fire 
644 disturbance effects in subalpine forests of north central Washington. Internal Report. $645 \quad$ USDA Forest Service Region 6 Report. pp. 32.

646 Schoennagel, T., Veblen, T.T., and Romme, W.H. 2004. The interaction of fire, fuels, and 647 climate across Rocky Mountain forests. BioScience 54:661-676.

648 Scott, J.H., and Reinhardt, E.D. 2001. Assessing crown fire potential by linking models of 649 surface and crown fire behavior. USDA, Forest Service, Rocky Mountain Research 650 Station Research Paper RMRS-RP-29, Fort Collins, CO.

651 Stevens-Rumann, C.S., and Morgan, P. In press. Wildfire as a tool: ecosystem impact of 652 repeated wildfires. Ecol. Appl.

653 Taylor, S.W., Wotton, B.M., Alexander, M.E., and Dairymple, G.N. 2004. Variation in wind 654 and crown fire behaviors in a northern jack pine black spruce forest. Can. J. Forest. $655 \quad$ Res. 34(8):1561-1576.

656 Teske, C.C., Seielstad, C.A., and Queen, L.P. 2012. Characterizing fire-on-fire interactions in 657 three wilderness areas. Fire Ecol. 8: 82-106.

658 Van Wagtendonk, J.W., Van Wagtendonk, K.A., and Thode, A.E. 2012. Factors associated 659 with the severity of intersecting fires in Yosemite National Park, California, USA. $660 \quad$ Fire Ecol. 8: 11-31.

661 Weiss, A. 2001. Topographic position and landform analysis. ESRI Users Conference. San 662 Diego, California, USA

663 Wimberly, M.C., Cochrane, M.A., Baer, A.D., and Pabst, K. 2009. Assessing fuel treatment 664 effectiveness using satellite imagery and spatial statistics. Ecol. Appl. 19: 1377-1384. 665 
TABLES

2 Table 1. Candidate predictor variables for sequential autoregression (SAR) modeling for the

3 four study areas (Tripod, Cascade, East Zone, and Kootenay*).

\begin{tabular}{|c|c|}
\hline Variable & Definition \\
\hline \multicolumn{2}{|l|}{ Wildfire data } \\
\hline PastSev-Past burn severity & $\begin{array}{l}\text { Categorical RdNBR (unburned/unchanged, low, } \\
\text { moderate, high) }\end{array}$ \\
\hline Edge-Distance to edge (m) & Distance from study fire perimeter \\
\hline TSF-Time since previous fire & Number of years since each pixel burned \\
\hline \multicolumn{2}{|l|}{ Fire weather } \\
\hline $\begin{array}{l}\text { MaxTemp-Maximum temperature } \\
\left({ }^{\circ} \mathrm{C}\right)\end{array}$ & Maximum temperature over progression interval \\
\hline $\begin{array}{l}\text { AvgTemp-Average temperature } \\
\left({ }^{\circ} \mathrm{C}\right)\end{array}$ & Average temperature over progression interval \\
\hline $\begin{array}{l}\text { MaxGust-Maximum wind speed } \\
(\mathrm{kph})\end{array}$ & Maximum recorded wind over progression interval \\
\hline $\begin{array}{l}\text { AvgGust-Average wind speed } \\
(\mathrm{kph})\end{array}$ & Average wind speed over progression interval \\
\hline MinRH-Minimum RH (\%) & Minimum relative humidity over progression interval \\
\hline \multicolumn{2}{|l|}{ Vegetation } \\
\hline $\begin{array}{l}\text { CBD-Canopy bulk density (kg } \\
\mathrm{m}^{3} \text { ) }\end{array}$ & Bulk density of available canopy fuel \\
\hline CovType-Cover Type & Derived from existing vegetation type \\
\hline CC-Canopy Cover $(\%)$ & Canopy cover of vegetation \\
\hline \multicolumn{2}{|l|}{ Topography } \\
\hline Elev-Elevation (m) & National elevation dataset \\
\hline Slope (degrees) & Slope gradient \\
\hline Solar radiation $\left(\mathrm{WH} \mathrm{m}^{-2}\right)$ & Potential incoming solar radiation (no cloud cover) \\
\hline TWI- Topographic wetness & Topographic Wetness Index \\
\hline TPI-Topographic position index & Discrete classified TPI raster \\
\hline Valley & Fuzzy valley bottom or 'valley-like' position \\
\hline Ridgetop & Fuzzy ridgetop or 'ridge-like' position \\
\hline
\end{tabular}


Table 2. Final sequential autoregression full models of relative differenced Normalized Burn Ratio (RdNBR) for the Tripod, Cascade, East Zone, and differenced Normalized Burn Ratio (dNBR) for the Kootenay study areas. $\mathrm{N}$ is the number of points analyzed.

\begin{tabular}{|c|c|c|c|c|}
\hline Model & Predictor variables & $\mathrm{N}$ & $\mathrm{R}^{2}$ & AIC \\
\hline Tripod & $\begin{array}{l}\text { CC, CovType, Edge, Elev, } \\
\text { MaxTemp, PastSev, Slope, Valley }\end{array}$ & 326,541 & 0.92 & $4,884,497$ \\
\hline East Zone & $\begin{array}{l}\text { CovType, Edge, Elev, MaxGust, } \\
\text { MaxTemp, PastSev, TWI, Valley }\end{array}$ & 905,805 & 0.73 & $12,705,742$ \\
\hline Cascade & $\begin{array}{l}\text { CC, CovType, Edge, MaxGust, } \\
\text { MaxTemp, PastSev, Slope, TSF, } \\
\text { Valley }\end{array}$ & 975,414 & 0.77 & $13,736,440$ \\
\hline Kootenay & $\begin{array}{l}\text { AvgTemp, Edge, Elev, Slope, } \\
\text { PastSev }\end{array}$ & 88,272 & 0.90 & $1,080,976$ \\
\hline
\end{tabular}


Table 3. Outputs for final SAR model for each variable. Past burn severity (PastSev) was categorized into unburned/unchanged (as the baseline), low, moderate, and high according to thresholds in Miller and Thode (2007). Cover type (CovType) was categorized into dry-mesic mixed conifer (DMC; as the baseline), douglas-fir/hemlock (DFHE), grassland/shrubland (GRASS/SHRUB), lodgepole pine dominated (LP), ponderosa pine dominated (PP), riparian areas (RIP), and subalpine fir dominate (SUBALP). Relationship to burn severity is distinguished by the "estimate," with the standard error (SE) and p-value (P), indicated for each variable.

\begin{tabular}{|c|c|c|c|c|c|c|c|c|c|c|c|c|}
\hline \multirow[b]{2}{*}{ Variables } & \multicolumn{3}{|c|}{ Tripod } & \multicolumn{3}{|c|}{ East Zone } & \multicolumn{3}{|c|}{ Cascade } & \multicolumn{3}{|c|}{ Kootenay } \\
\hline & Estimate & $\overline{\mathrm{SE}}$ & $P$ & Estimate & $\mathrm{SE}$ & $P$ & Estimate & $\mathrm{SE}$ & $P$ & Estimate & SE & $P$ \\
\hline Intercept & -428.00 & 29.40 & $<0.0001$ & -71.43 & 7.37 & $<0.0001$ & 704.00 & 31.60 & $<0.0001$ & 129.60 & 36.78 & 0.0004 \\
\hline Edge & 0.13 & 0.01 & $<0.0001$ & 0.03 & 0.01 & $<0.0001$ & 0.04 & 0.01 & $<0.0001$ & 0.18 & 0.008 & $<0.0001$ \\
\hline Valley & -0.12 & 0.02 & $<0.0001$ & -0.52 & 0.02 & $<0.0001$ & -0.67 & 0.25 & $<0.0001$ & - & - & - \\
\hline MaxTemp & 1.57 & 0.09 & $<0.0001$ & 3.42 & 0.13 & $<0.0001$ & 7.30 & 0.20 & $<0.0001$ & - & - & - \\
\hline AvgTemp & - & - & - & - & - & - & - & - & - & 8.23 & 0.79 & $<0.0001$ \\
\hline Past Sev - Low & -16.60 & 2.12 & $<0.0001$ & -16.85 & 1.29 & $<0.0001$ & -284.00 & 27.50 & $<0.0001$ & 0.42 & 7.84 & 0.96 \\
\hline Past Sev - Moderate & -28.90 & 2.71 & $<0.0001$ & -17.00 & 1.76 & $<0.0001$ & -266.00 & 27.40 & $<0.0001$ & -19.68 & 8.83 & 0.03 \\
\hline Past Sev - High & -42.10 & 3.18 & $<0.0001$ & -25.50 & 2.40 & $<0.0001$ & -246.00 & 27.50 & $<0.0001$ & -54.16 & 13.58 & $<0.0001$ \\
\hline Slope & 1.38 & 0.13 & $<0.0001$ & - & - & - & -0.48 & 0.11 & $<0.0001$ & -0.18 & 0.04 & 0.03 \\
\hline TWI & - & - & - & -5.15 & 0.18 & $<0.0001$ & - & - & - & - & - & - \\
\hline CovType DFHE & 4.44 & 8.16 & 0.59 & 7.08 & 1.45 & $<0.0001$ & 0.34 & 2.69 & 0.90 & - & - & - \\
\hline CovType GRASS/SHRUB & 3.48 & 1.42 & 0.014 & 13.90 & 1.74 & $<0.0001$ & 8.10 & 2.91 & 0.005 & - & - & - \\
\hline CovType LP & 2.45 & 0.91 & 0.0070 & 7.72 & 1.86 & $<0.0001$ & 8.84 & 2.84 & 0.002 & - & - & - \\
\hline
\end{tabular}




\begin{tabular}{|c|c|c|c|c|c|c|c|c|c|c|c|c|}
\hline CovType PP & -6.01 & 2.81 & 0.033 & 3.09 & 2.08 & 0.13 & -2.41 & 4.40 & 0.58 & - & - & - \\
\hline CovType RIP & -44.60 & 3.02 & $<0.0001$ & -1.58 & 2.85 & 0.58 & -8.36 & 3.53 & 0.02 & - & - & - \\
\hline CovType SUBALP & 2.93 & 0.89 & 0.0010 & 10.20 & 1.66 & $<0.0001$ & 10.90 & 2.79 & $<0.0001$ & - & - & - \\
\hline Elev & 0.47 & 0.02 & $<0.0001$ & 0.31 & 0.01 & $<0.0001$ & - & - & - & 0.094 & 0.019 & $<0.0001$ \\
\hline $\mathrm{CC}$ & 0.70 & 0.03 & $<0.0001$ & - & - & - & 6.44 & 0.027 & $<0.0001$ & - & - & - \\
\hline MaxGust & - & - & - & 1.26 & 0.23 & $<0.0001$ & -3.55 & 0.20 & $<0.0001$ & - & - & - \\
\hline TSF & - & - & - & - & - & - & -3.30 & 0.31 & $<0.0001$ & - & - & - \\
\hline
\end{tabular}


Table 4. Results of cover type SAR analysis, performed on points identified as a "low elevation forest type" (Douglas-fir/hemlock, ponderosa pine, dry-mesic mixed-conifer) and a "high elevation forest type" (lodgepole pine, subalpine fir). Values are the regression estimate of time since fire and past burn severity (low moderate, high) in comparison to previously unburned/unchanged points. Asterisks indicate significance at $\alpha=0.05$ level.

\begin{tabular}{|c|c|c|c|c|c|}
\hline Area & $\begin{array}{l}\text { Elevation } \\
\text { (Forest } \\
\text { type) }\end{array}$ & $\begin{array}{l}\text { time since } \\
\text { fire }\end{array}$ & $\begin{array}{l}\text { Past severity- } \\
\text { low }\end{array}$ & $\begin{array}{l}\text { Past } \\
\text { severity- } \\
\text { moderate }\end{array}$ & $\begin{array}{l}\text { Past severity- } \\
\text { high }\end{array}$ \\
\hline \multirow{2}{*}{ Cascade } & High & $0.09 *$ & $-15.88 *$ & -1.71 & $22.01 *$ \\
\hline & low & $0.23 *$ & $-29.20 *$ & $-14.91 *$ & $17.08^{*}$ \\
\hline \multirow[t]{2}{*}{ East Zone } & high & $0.63 *$ & $-49.92 *$ & $-64.01 *$ & $-71.58 *$ \\
\hline & low & $0.41 *$ & $-36.30^{*}$ & $-37.07 *$ & $-29.61 *$ \\
\hline \multirow[t]{2}{*}{ Tripod } & high & $1.30^{*}$ & $-100.08 *$ & $-188.58 *$ & $-281.46^{*}$ \\
\hline & low & $5.28 *$ & $-378.03 *$ & $-465.61 *$ & $-520.36^{*}$ \\
\hline
\end{tabular}




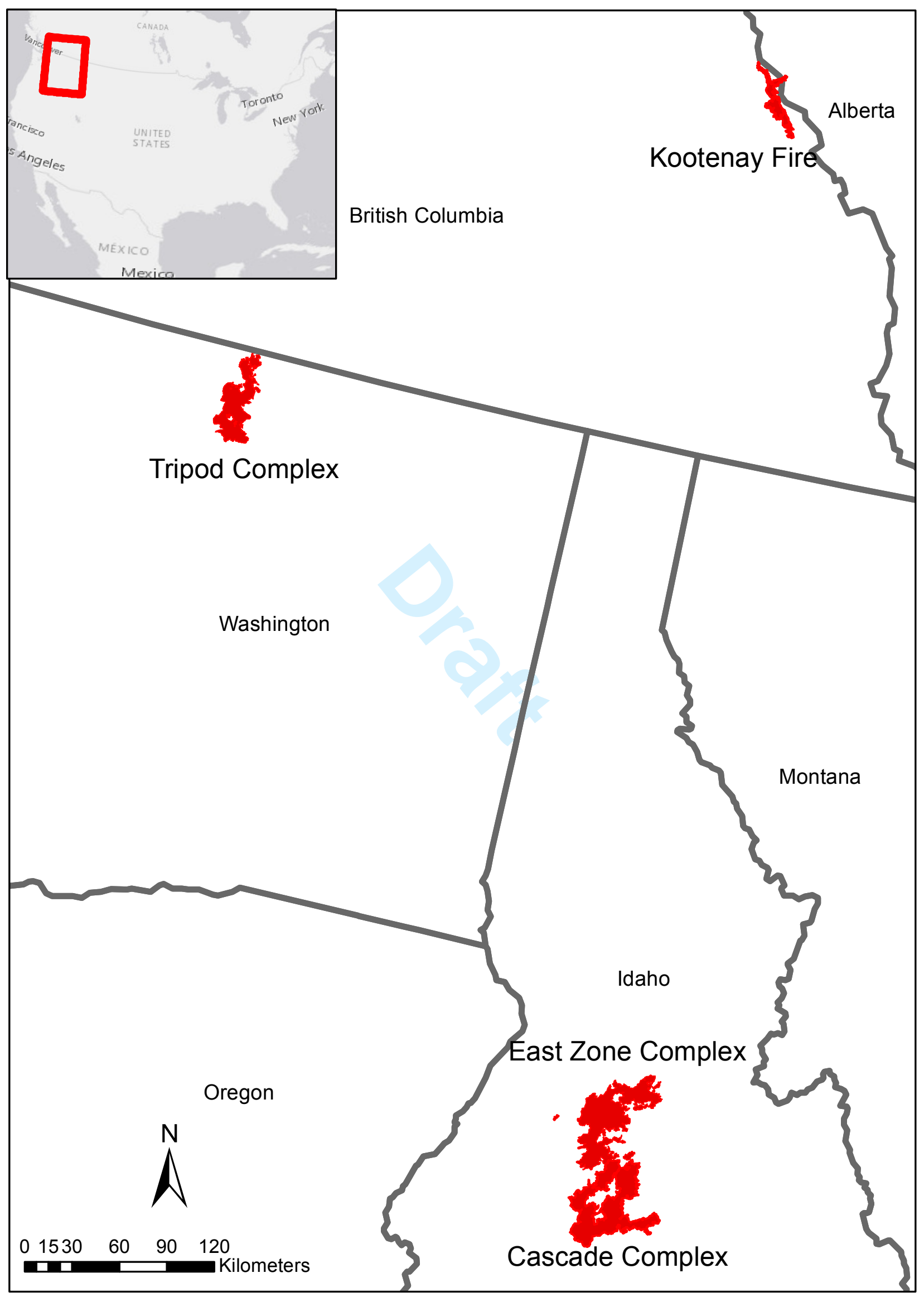




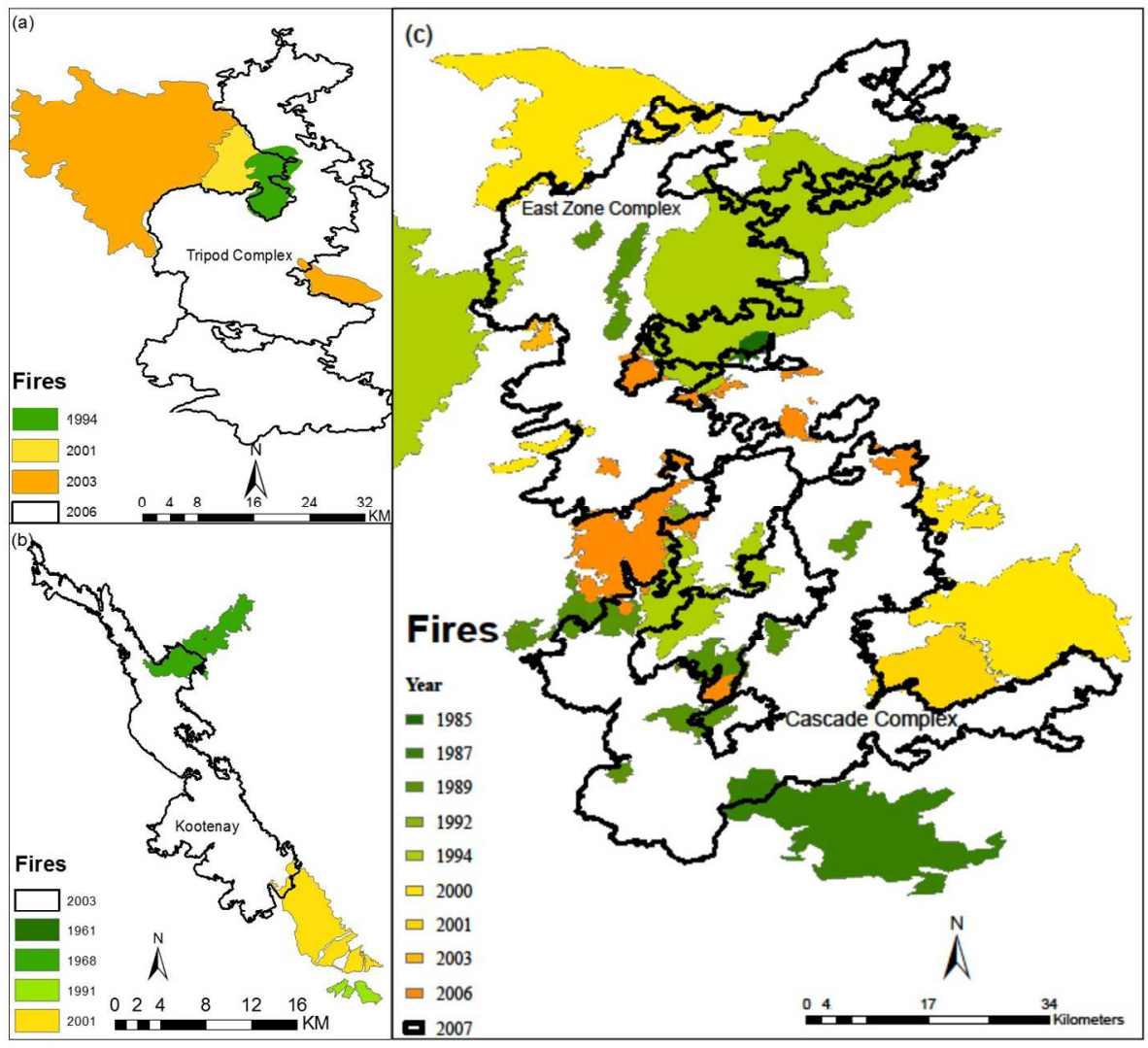

Figure 2. (a) Tripod Complex, (b) Kootenay Fire, (c) East Zone Complex and Cascade Complex with perimeters of previous wildfire. Older past fires are indicated with greens, while more recent fires are indicated in orange and yellows.

$287 \times 274 \mathrm{~mm}(150 \times 150 \mathrm{DPI})$ 

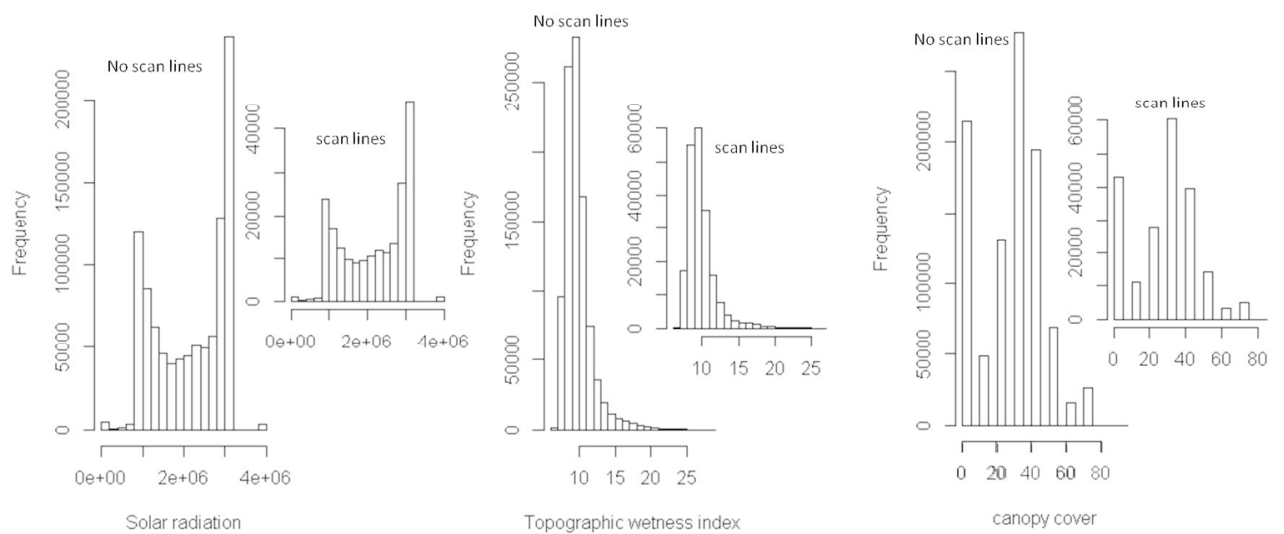

Figure 4.

Figure 3. Distribution of topographic (solar radiation and topographic wetness index) and vegetation (canopy cover) variables using our East Zone dataset which excluded the scan lines compared to a dataset of the pixels within the scan lines which we were unable to use due to lack of burn severity information.

Distributions are very similar for both, reducing the possibility of bias with the missing data.

$304 \times 139 \mathrm{~mm}(150 \times 150 \mathrm{DPI})$ 

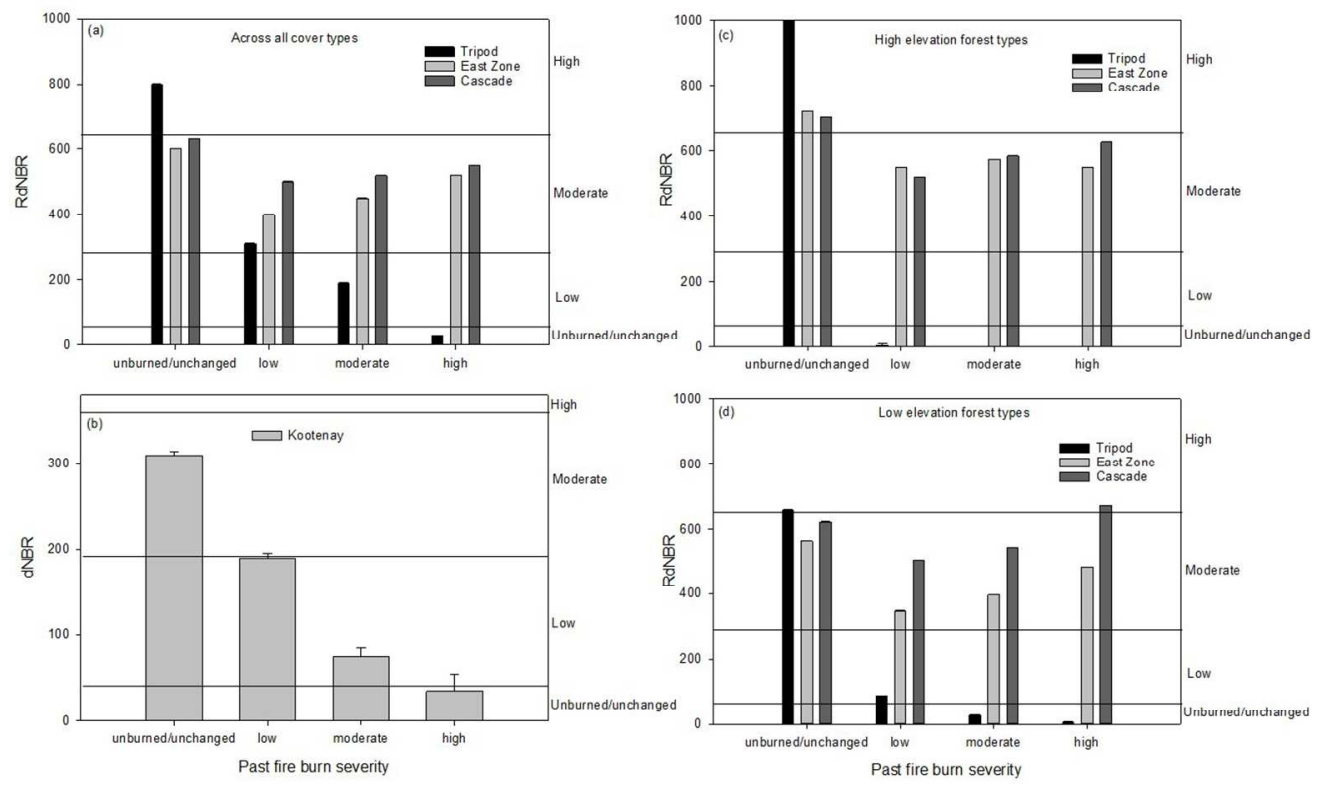

Figure 4

Figure 4. RdNBR or dNBR response by past fire burn severity on each fire. The left axis is a continuous RdNBR/dNBR metric, while the right axis identifies the burn severity thresholds we used based on Miller and Thode (2007) of unchanged/unburned, low, moderate, and high severity. (a) is the RdNBR response to burn severity on the Tripod (black), East Zone (light gray), and Cascade (dark gray) Fires across all cover types. (b) is the dNBR response to past burn severity on the Kootenay Fire. (c) is the RdNBR response to past burn severity in "high elevation" forest types. (d) is the RdNBR response to past burn severity in "low elevation" forest types.

$225 \times 150 \mathrm{~mm}(150 \times 150 \mathrm{DPI})$ 

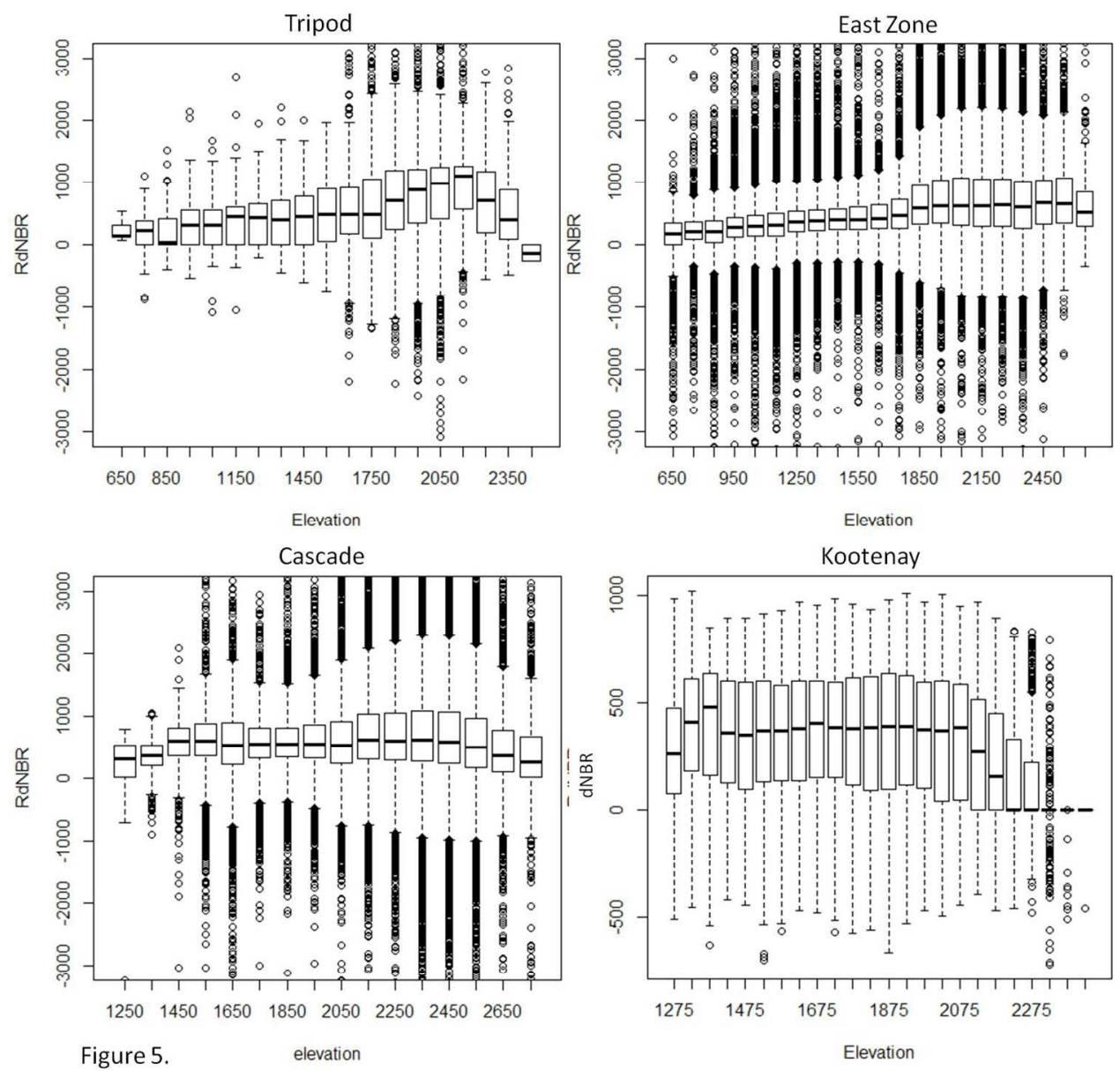

Figure 5. Box and whisker plots of RdNBR and dNBR response by elevation. Tripod is in the top left, East Zone in the top right, Cascade on the bottom left, and Kootenay in the bottom right.

$282 \times 277 \mathrm{~mm}(150 \times 150 \mathrm{DPI})$ 


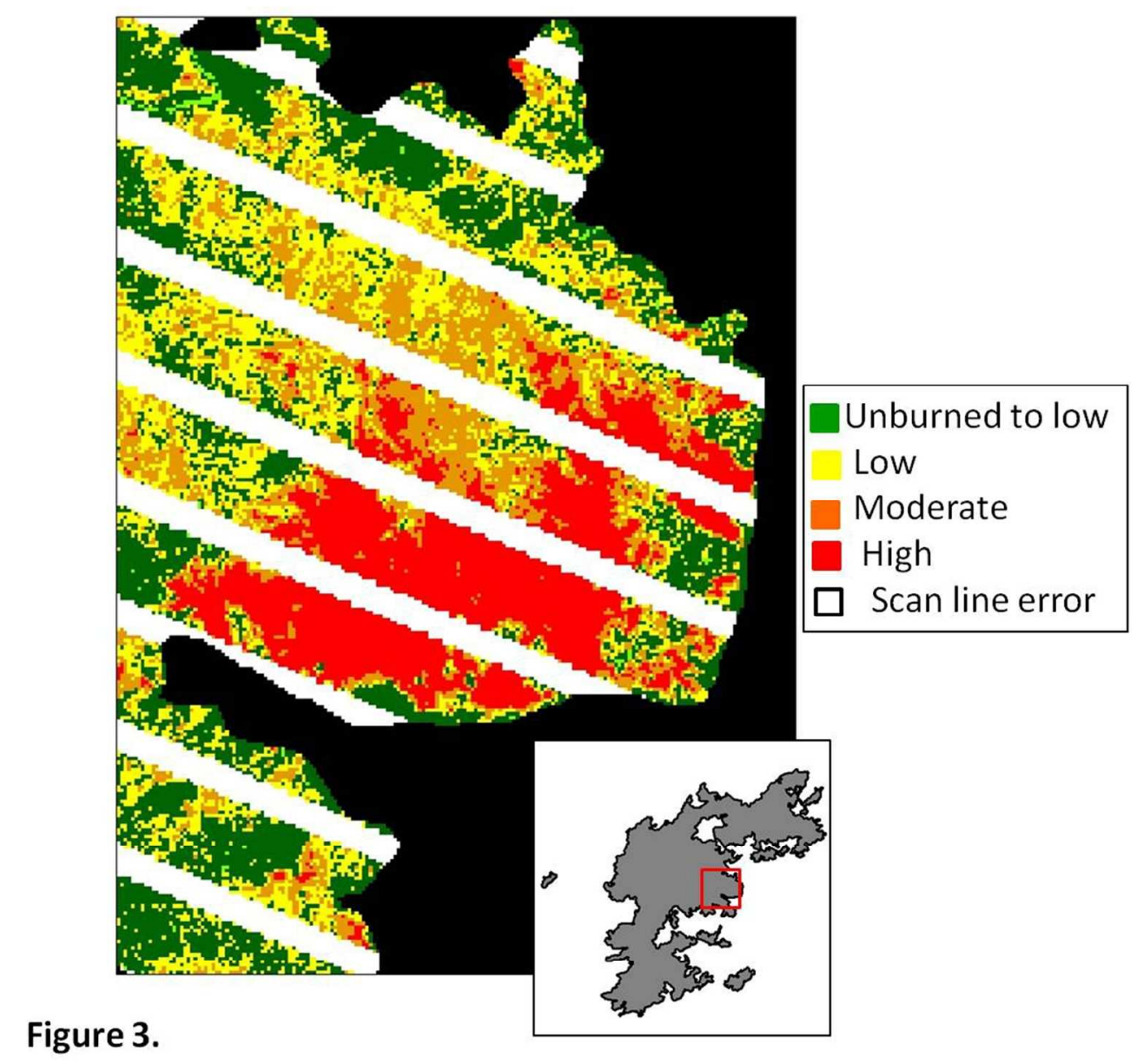

Supplemental Figure 1: Example of scan line errors in the Landsat satellite data on the East Zone Complex Fire. White lines indicate missing data; lines are $150 \mathrm{~m}$ wide.

$187 \times 190 \mathrm{~mm}(150 \times 150 \mathrm{DPI})$ 